\title{
Nutritional and Functional Assessment of Hospitalized Elderly: Impact of Sociodemographic Variables
}

\author{
Emam M. M. Esmayel, ${ }^{1}$ Mohsen M. Eldarawy, ${ }^{1}$ Mohamed M. M. Hassan, ${ }^{1}$ \\ Hassan Mahmoud Hassanin, ${ }^{1}$ Walid M. Reda Ashour, ${ }^{2}$ and Wael Mahmoud ${ }^{2}$ \\ ${ }^{1}$ Department of Internal Medicine, Faculty of Medicine, Zagazig University, Zagazig 44519, Egypt \\ ${ }^{2}$ Department of Neurology, Faculty of Medicine, Zagazig University, Zagazig 44519, Egypt
}

Correspondence should be addressed to Emam M. M. Esmayel; mmdemmo@yahoo.com

Received 30 May 2013; Revised 20 July 2013; Accepted 21 July 2013

Academic Editor: F. Richard Ferraro

Copyright (C) 2013 Emam M. M. Esmayel et al. This is an open access article distributed under the Creative Commons Attribution License, which permits unrestricted use, distribution, and reproduction in any medium, provided the original work is properly cited.

Background. This work was constructed in order to assess the nutritional and functional status in hospitalized elderly and to study the associations between them and sociodemographic variables. Methods. 200 elderly patients ( $>65$ years old) admitted to Internal Medicine and Neurology Departments in nonemergency conditions were included. Comprehensive geriatric assessments, including nutritional and functional assessments, were done according to nutritional checklist and Barthel index, respectively. Information was gathered from the patients, from the ward nurse responsible for the patient, and from family members who were reviewed. Results. According to the nutritional checklist, $56 \%$ of participants were at high risk, $18 \%$ were at moderate risk of malnutrition, and $26 \%$ had good nutrition. There was a high nutritional risk in patients with low income and good nutrition in patients with moderate income. Also, there was a high nutritional risk in rural residents (61.9\%) in comparison with urban residents (25\%). Barthel index score was significantly lower in those at high risk of malnutrition compared to those at moderate risk and those with good nutrition. Conclusions. Hospitalized elderly are exposed to malnutrition, and malnourished hospitalized patients are candidates for functional impairment. Significant associations are noticed between both nutritional and functional status and specific sociodemographic variables.

\section{Introduction}

In recent years, there has been a sharp increase in the number of older persons worldwide [1]. It is estimated that almost half of the adults who are hospitalized are 65 years of age or older, although those older than 65 years represent only 12.5 percent of the population [2]. Aging is associated with various physiological changes and needs, which make elderly people vulnerable to malnutrition [3].

Malnutrition is a major geriatric problem associated with poor health status and high mortality, and the impact of a patient's nutritional condition on the clinical outcome has been widely recognized [4]. Application of nutritional support based on nutritional screening results significantly reduced the incidence of complications and the length of hospital stay [5]. The prevalence of malnutrition varies considerably depending on the population studied and the criteria used for the diagnosis [3].

The nutritional screening checklist (NCL) is the most frequently used nutritional screening tool for communitydwelling older adults. It is intended to prevent impairment by identifying and treating nutritional problems before they become a detriment to the lives of older adults [6]. Nutrition and physical activity impact functional changes through changes in body composition [7].

Tanimoto et al. recently reported that sarcopenia, defined by muscle mass, muscle strength, and physical performance, was associated with functional decline over a 2-year period in elderly Japanese [8]. Also, Andre et al. found that the percentage of elderly with dependence was significantly higher in the malnourished (87.6\%) than in well-nourished elderly (50.9\%) [3]. 
Dependency interferes with the health and quality of life, not only for the elderly, but also for relatives and healthcare providers [9]. Assessment of functional capacity is a key element in geriatric health, as it can help in identifying what services or programs are needed [10]. The Barthel self-care index (BSI) is proposed as the standard index for clinical and research purposes [11], and it has proved to be a good predictor of in-hospital mortality [12]. Matzen et al. [13] recently concluded that it is a strong independent predictor of survival in older patients admitted to an acute geriatric unit, and they also suggested that it may have a potential role in decision making for the clinical management of frail geriatric inpatients. It is also found useful for evaluating the functional ability of elderly patients being treated in outpatient care [14].

However, less attention is given to the underlying risk of functional decline and the vulnerability to hospitalassociated complications [2]. Also, information about the nutritional and functional status and its correlation with sociodemographic variables in Egypt among hospitalized elderly are scarce; the sociodemographic data will focus a bit on which group is at increased risk of nutritional and functional instability, and hence which group deserves more attention. This study was conducted in order to clarify the impact of sociodemographic factors on nutritional and functional status of the elderly in, addition to the interrelationship between both.

\section{Methods}

This study has been carried out on 200 elderly patients ( $>65$ years old) admitted to Internal Medicine and Neurology Departments, Zagazig University Hospitals, which are educational hospitals serving Sharkia governorate, during the period between October 2009 and October 2010. The admission was due to gastrointestinal troubles in 88 patients, cardiac troubles in 28 , chest troubles in 40 , neurological in 28 , or other causes in 16 patients.

According to age, they were classified into young old (6574.9 years), old old ( $75-84.9$ years), and oldest old ( $\geq 85$ years). Patients who required treatment in specialized units such as the intensive care units, were excluded. All participants gave informed consents and the study had approval from local ethical committee.

Information was gathered on admission by the treating physician from the patients, from the ward nurse responsible for the patient, and from family members who reviewed. All the patients were subjected to full history taking and clinical examination.

Nutritional assessment was done by physical examination by searching for clinical signs of nutritional deficiencies. We used the NCL for nutritional screening which included 10 items with a total score of 21 points. A score from 0 to 2 was considered as good nutrition, 3 to 5 as moderate nutritional risk, and 6 or more as high nutritional risk [15]. The nutritional checklist includes illness and tooth or mouth problems affecting feeding, number of meals per day, and types of foods and drinks. Also ability to eating alone, to cook, shop or feed oneself, and weight gain or loss, are included. One study using the NCL was carried out and the researchers found that, when compared to nutritional assessment criteria (anthropometric, dietary, and laboratory data), the NCL identified $83 \%$ of the population as being at high risk compared to $74 \%$ using the nutritional assessment criteria [16]. It has been suggested that the NCL is more appropriately used in observational epidemiological studies than for population screening [17].

Functional assessment was done using the Barthel selfcare index of activities of daily living [18]. The index included bowels, bladder, grooming, toilet use, feeding, transfer, mobility, dressing, stairs, and bathing. Total possible scores range from 0 to 20, with lower scores indicating increased disability. Sociodemographic information and nutritional checklist were collected by direct interviews, while Barthel index was collected using chart reading.

2.1. Statistical Analysis. Data were checked, entered, and analyzed using SPSS version 15 for data processing and statistics. Continuous variables were tested for normal distribution and expressed as mean \pm standard deviation and compared by Student's $t$ test. Categorical variables were compared with the chi-square test. For all analyses, $P$ value $<0.05$ was considered statistically significant.

\section{Results}

Demographic data of the studied groups are presented in Table 1. A total of 200 elderly patients were included in the study. The large majority of patients were illiterate $(84 \%)$ and none of them were on regular exercise. As for marital state, $56 \%$ were widowed and $40 \%$ married with only $4 \%$ having no children. $56 \%$ had low income with only $2 \%$ having means of transportation (Table 2).

According to NCL, $56 \%$ of the participants were at high risk and $26 \%$ had good nutrition (Table 3 ). Nutritional checklist score was worst in age group $\geq 85$ years, while age has no significant effect on BSI (Table 4). There was a high nutritional risk in rural residents (61.9\%) in comparison with urban residents (25\%); the mean of BSI was higher in patients from rural than that of urban areas with no significant difference (Table 5).

High nutritional risk was found in $52.4 \%$ of illiterate patients and $75 \%$ of educated patients, while there was no association between BSI and education $(P=0.56)$ (Table 6). No significant association was found between BSI and gender $(P=0.22)$ and also between NCL and gender $(P=0.16)$ (Table 7).

There was a significant association between NCL and income $(P=0.017)$, as there was a high nutritional risk in patients with low income and good nutrition in patients with moderate income, in contrast there was no association between BSI and income $(P=0.47)$ (Table 8$)$. A significant association between NCL and BSI $(<0.001)$ indicates that both nutrition and functional ability go together (Table 9 ). 
TABLE 1: Demographic data of patients.

\begin{tabular}{lcc}
\hline & $N$ & $\%$ \\
\hline Age & & \\
$65<75$ & 164 & 82 \\
$75<85$ & 28 & 14 \\
$\geq 85$ & 8 & 4 \\
Gender & & \\
Male & 112 & 56 \\
Female & 88 & 44 \\
Residence & & \\
Rural & 168 & 84 \\
Urban & 32 & 16 \\
\hline
\end{tabular}

\section{Discussion}

Older patients tend to have multiple organic, psychological, and social problems [19]. Their functional and physiological capacities are often diminished and the adverse effects of drugs are more pronounced. The concept of Comprehensive Geriatric Assessment (CGA) has evolved because of the many problems of elderly subjects [20]. Our study was concerned with patients admitted to Internal Medicine department with age above 65 years. Majority of age group was young old and represented $88 \%$ while the oldest old represented $4 \%$ of patients included in the study.

As regards assessment of nutrition, considerable number of studies have examined the nutritional status of institutionalized elderly people and reported prevalence figures for malnutrition and nutritional problems [21]. According to the American Dietetic Association (ADA), the nutrient requirements of elderly peopleare not fully understood, although it is known that the physiological and functional changes that occur with agingcan result in changes in nutrient needs [22].

The American Academy of Family Physicians and the National Council of Aging in the United States previously formed the Nutrition Screening Initiative for the development of strategies to detect nutritional risks among older people. One of the strategies included the development of a ten-question checklist, the NCL [23]. This checklist, which was designed to be self-administered, could also be administered by a healthcare professional.

According to NCL, our results showed that about 56\% of patients had high nutritional risk. A study conducted in Canada indicated that $37-62 \%$ of elderly were at risk of the poor nutrition [24], and the percent was $50.3 \%$ in another study in India [25]. A recent study in China [4] found that the overall prevalence of under nutrition and nutritional risk was $17.8 \%$ and $41.5 \%$, respectively, using the NCL. Another recent study in Makkah found that among 102 recently hospitalized elderly and according to the mini nutritional assessment (MNA) tool, 22.6\% were classified as malnourished, $57.8 \%$ were at risk of malnutrition, and $19.6 \%$ were well nourished [1]. Also, another study found that $10.2 \%$ of elderly individuals were malnourished and $39.9 \%$ were at risk of malnutrition according to the MNA screening tool [5]. Differences in prevalence rates of malnutrition among
TABLE 2: Sociodemographic variables in studied patients.

\begin{tabular}{|c|c|c|}
\hline \multicolumn{3}{|l|}{ Education } \\
\hline Illiterate & 168 & 84 \\
\hline Educated & 32 & 16 \\
\hline \multicolumn{3}{|l|}{ Vocation } \\
\hline Retired & 64 & 32 \\
\hline Farmer & 52 & 26 \\
\hline Housewife & 72 & 36 \\
\hline Crafts man & 12 & 6 \\
\hline \multicolumn{3}{|l|}{ Habits } \\
\hline \multicolumn{3}{|l|}{ Exercise } \\
\hline Yes & 0 & 0 \\
\hline No & 200 & 100 \\
\hline \multicolumn{3}{|l|}{ Sleep } \\
\hline Satisfied & 84 & 42 \\
\hline Not satisfied & 116 & 58 \\
\hline \multicolumn{3}{|l|}{ Sexual activity } \\
\hline No & 156 & 78 \\
\hline Satisfied & 8 & 4 \\
\hline Not satisfied & 36 & 16 \\
\hline \multicolumn{3}{|l|}{ Substance abuse } \\
\hline Yes & 56 & 28 \\
\hline No & 144 & 72 \\
\hline \multicolumn{3}{|l|}{ Marital status } \\
\hline Yes & 80 & 40 \\
\hline No & 4 & 2 \\
\hline Widowed & 112 & 56 \\
\hline Divorced & 4 & 2 \\
\hline \multicolumn{3}{|l|}{ Children } \\
\hline Yes & 192 & 96 \\
\hline No & 8 & 4 \\
\hline \multicolumn{3}{|c|}{ Presence of close friends } \\
\hline Yes & 136 & 68 \\
\hline No & 64 & 32 \\
\hline \multicolumn{3}{|l|}{ Income } \\
\hline Low & 112 & 56 \\
\hline Moderate & 88 & 44 \\
\hline High & 0 & 0 \\
\hline \multicolumn{3}{|l|}{ Transportation } \\
\hline Available & 196 & 98 \\
\hline Not available & 4 & 2 \\
\hline
\end{tabular}

the different studies may be due to difference in selection criteria of elderly, different assessment tools, and differences in sociodemographic variables.

In this study, there was an association between NCL and age group. We found that $100 \%$ of oldest old had high nutritional risk and $85.7 \%$ of old old have high nutritional risk, but the percent in young old was $48.8 \%$. Our results agree with that obtained by Fang et al. [4] who found that the prevalence of nutritional risk was significantly higher in patients $>70$ years of age than in patients $<70$ years $(64 \%$ versus $32 \%, P<0.001)$. Yap et al. found that high nutritional 
TABLE 3: Nutritional and functional assessment of studied patients.

\begin{tabular}{lcrc}
\hline & Good nutrition & 52 patients & $26 \%$ \\
Nutritional assessment (NCL) & Moderate risk of malnutrition & 36 patients & $18 \%$ \\
& High risk of malnutrition & 112 patients & $56 \%$ \\
\hline \multirow{2}{*}{ Functional assessment (BSI) } & Range & $8-20$ & $16 \pm 4.1$ \\
\hline
\end{tabular}

TABLE 4: Association between nutritional checklist (NCL) and Barthel self-care index (BSI) with age.

\begin{tabular}{|c|c|c|c|c|c|c|c|c|}
\hline & \multicolumn{6}{|c|}{ NCL } & \multicolumn{2}{|c|}{ BSI } \\
\hline & \multicolumn{2}{|c|}{ Good nutrition } & \multicolumn{2}{|c|}{ Moderate risk } & \multicolumn{2}{|c|}{ High risk } & \multirow[t]{2}{*}{ Range } & \multirow[t]{2}{*}{ Mean \pm SD } \\
\hline & No. & $\%$ & No. & $\%$ & No. & $\%$ & & \\
\hline \multicolumn{9}{|l|}{ Age } \\
\hline Young old $(N=164)$ & 48 & 29.3 & 36 & 22.0 & 80 & 48.8 & $8-20$ & $16.5 \pm 3.84$ \\
\hline Old old $(N=28)$ & 4 & 14.3 & 0 & 0.0 & 24 & 85.7 & $8-20$ & $13.4 \pm 5.2$ \\
\hline Oldest old $(N=8)$ & 0 & 0 & 0 & 0 & 8 & 100 & $15-18$ & $16.5 \pm 2.1$ \\
\hline$X^{2}$ & \multicolumn{6}{|c|}{10.4} & \multicolumn{2}{|c|}{3.65} \\
\hline$P$ & \multicolumn{4}{|c|}{0.001} & & & \multicolumn{2}{|c|}{0.018} \\
\hline
\end{tabular}

TABLE 5: Association between nutritional checklist (NCL) and Barthel self-care index (BSI) with residence.

\begin{tabular}{|c|c|c|c|c|c|c|c|c|}
\hline & \multicolumn{6}{|c|}{ NCL } & \multicolumn{2}{|c|}{ BSI } \\
\hline & \multicolumn{2}{|c|}{ Good nutrition } & \multicolumn{2}{|c|}{ Moderate risk } & \multicolumn{2}{|c|}{ High risk } & \multirow[t]{2}{*}{ Range } & \multirow[t]{2}{*}{ Mean \pm SD } \\
\hline & $N$ & $\%$ & $N$ & $\%$ & $N$ & $\%$ & & \\
\hline \multicolumn{9}{|l|}{ Residence } \\
\hline Rural $N=168$ & 40 & 23.8 & 24 & 14.3 & 104 & 61.9 & $8-20$ & $15.6 \pm 4.6$ \\
\hline Urban $N=32$ & 12 & 37.5 & 12 & 37.5 & 8 & 25 & $9-20$ & $7.8 \pm 3.67$ \\
\hline$X^{2}$ & \multicolumn{6}{|c|}{8.26} & \multicolumn{2}{|c|}{1.81} \\
\hline$P$ & \multicolumn{6}{|c|}{0.016} & \multicolumn{2}{|c|}{0.07} \\
\hline
\end{tabular}

TABLE 6: Association between nutritional checklist (NCL) and Barthel self-care index (BSI) with education.

\begin{tabular}{|c|c|c|c|c|c|c|c|c|}
\hline & \multicolumn{6}{|c|}{ NCL } & \multicolumn{2}{|c|}{ BSI } \\
\hline & \multicolumn{2}{|c|}{ Good nutrition } & \multicolumn{2}{|c|}{ Moderate risk } & \multicolumn{2}{|c|}{ High risk } & \multirow[t]{2}{*}{ Range } & \multirow[t]{2}{*}{ Mean \pm SD } \\
\hline & $N$ & $\%$ & $N$ & $\%$ & $N$ & $\%$ & & \\
\hline \multicolumn{9}{|l|}{ Education } \\
\hline Illiterate $N=168$ & 52 & 31 & 28 & 16.7 & 88 & 52.4 & $8-20$ & $15.97 \pm 3.89$ \\
\hline Educated $N=32$ & 0 & 0 & 8 & 25 & 24 & 75 & $8-20$ & $16.6 \pm 4.9$ \\
\hline$X^{2}$ & \multicolumn{6}{|c|}{6.7} & \multicolumn{2}{|c|}{0.85} \\
\hline$P$ & \multicolumn{4}{|c|}{0.035} & & & \multicolumn{2}{|c|}{0.56} \\
\hline
\end{tabular}

TABLE 7: Association between nutritional checklist (NCL) and Barthel self-care index (BSI) with gender.

\begin{tabular}{|c|c|c|c|c|c|c|c|c|}
\hline & \multicolumn{6}{|c|}{ NCL } & \multicolumn{2}{|c|}{ BSI } \\
\hline & \multicolumn{2}{|c|}{ Good nutrition } & \multicolumn{2}{|c|}{ Moderate risk } & \multicolumn{2}{|c|}{ High risk } & \multirow[t]{2}{*}{ Range } & \multirow[t]{2}{*}{ Mean \pm SD } \\
\hline & $N$ & $\%$ & $N$ & $\%$ & $N$ & $\%$ & & \\
\hline \multicolumn{9}{|l|}{ Gender } \\
\hline Male $N=112$ & 24 & 21.4 & 16 & 14.3 & 72 & 64.3 & $8-20$ & $15.4 \pm 4.4$ \\
\hline Female $N=88$ & 28 & 31.8 & 20 & 22.7 & 40 & 45.5 & $9-20$ & $16.9 \pm 3.4$ \\
\hline$X^{2}$ & \multicolumn{6}{|c|}{3.56} & \multicolumn{2}{|c|}{4.35} \\
\hline$P$ & \multicolumn{6}{|c|}{0.16} & \multicolumn{2}{|c|}{0.22} \\
\hline
\end{tabular}


TABLE 8: Association between nutritional checklist (NCL) and Barthel self-care index (BSI) with financial security (income).

\begin{tabular}{|c|c|c|c|c|c|c|c|c|}
\hline & \multicolumn{6}{|c|}{ NCL } & \multicolumn{2}{|c|}{ BSI } \\
\hline & \multicolumn{2}{|c|}{ Good nutrition } & \multicolumn{2}{|c|}{ Moderate risk } & \multicolumn{2}{|c|}{ High risk } & \multirow[t]{2}{*}{ Range } & \multirow[t]{2}{*}{ Mean \pm SD } \\
\hline & $N$ & $\%$ & $N$ & $\%$ & $N$ & $\%$ & & \\
\hline \multicolumn{9}{|c|}{ Financial security (income) } \\
\hline Low $N=112$ & 20 & 17.9 & 24 & 21.4 & 68 & 60.7 & $8-20$ & $15.8 \pm 3.9$ \\
\hline Moderate $N=88$ & 36 & 40.9 & 8 & 9.1 & 44 & 50 & $8-20$ & $16.4 \pm 4.2$ \\
\hline$X^{2}$ & \multicolumn{6}{|c|}{11.97} & \multicolumn{2}{|c|}{0.71} \\
\hline$P$ & \multicolumn{6}{|c|}{0.017} & \multicolumn{2}{|c|}{0.47} \\
\hline
\end{tabular}

TABLE 9: Association between Barthel self-care index (BSI) with nutritional checklist (NCL).

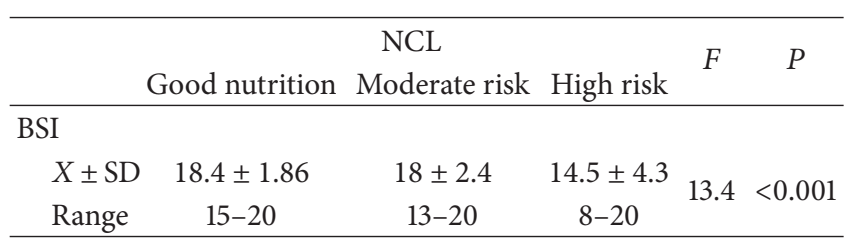

risk was more in older patients but with no significant association with age [26].

Also in this study, we found that high nutritional risk represented $52.4 \%$ in illiterate patients and about $75 \%$ in educated patients; however, we cannot depend on this finding due to the large difference in sample size between illiterate and educated patients ( $84 \%$ versus $16 \%$, resp.). However, the previous study [26] found no significant correlation between NCL and education, and the percent of patients with high nutritional risk was $26.2 \%$ and $33.6 \%$ in educated versus illiterate patients, respectively. Increased nutritional risk in males was $64.3 \%$ versus $45.5 \%$ in females $(P=$ 0.16 ), and this was confirmed by MacLellan and van Til [24]. Contrarily, Rambousková et al. [27] concluded that institutionalized women should be considered a nutritionally vulnerable population group; the reason for this difference may be the higher average age of women versus men (86.1 \pm 6.15 versus $81.5 \pm 7.97$ years) in their study. Meanwhile, Fang et al. [4] found no gender difference in the prevalence of nutritional risk. We found a high nutritional risk in rural residents (61.9\%) in comparison with urban residents (25\%); this may be due to a higher income and a better nutrition knowledge in urban areas.

High nutritional risk in patients with low income was $60.7 \%$, while it was about $50 \%$ in patients with moderate income. A study in Nigeria concluded that males had significantly higher income, higher socioeconomic status scores and were also less vulnerable to malnutrition than females $(P<0.05)$ [28]. Poverty is a nonphysiological cause of under nutrition in older people [29].

As regards functional assessment, the Barthel self care index of activities of daily living, first developed in 1965 [30] and later modified by Granger et al. [31], measures functional disability by quantifying patient performance in 10 activities of daily life. The Barthel Index has been reported to have excellent reliability and validity and adequate responsiveness to change, in measuring neurologic physical disability. Hobart et al. compared psychometric properties of the Barthel index with newer and lengthier scales, the Functional Independence Measure (FIM) and the Functional Independence Measure + Functional Assessment Measure (FIM+FAM), in patients undergoing rehabilitation. This study suggested that the newer and more extensive rating scales of FIM and FIM+FAM offered few advantages over the more practical and economical Barthel index [32]. Similar results were observed in studies of patients with multiple sclerosis and stroke $[33,34]$.

In this study, we found a significant correlation between disability and age, where functional activity decreased with advancing age. Hairi et al. showed that advancing age was significantly associated with functional limitation [35]. We did not find significant correlation between disability and income, however, a study done ona random sample of persons, 55-85 years of age, drawn from the population registers of 11 municipalities found that low socioeconomic status had been associated with physical disability [36]. Unless low socioeconomic status is associated with handwork, the elderly will be more susceptible to physical inactivity and lack of exercise.

Gender had no effect on functional activity in our study. Bergamini et al. found that older Italian men and women showed similar prevalence of functional limitation, $31 \%$ and $28 \%$, respectively [37]. However, Hairi et al. found that female gender was significantly associated with functional limitation; they suggested that disadvantages resulting from limited education may contribute to the greater physical disability and functional limitation burden experienced by older women in their study [35].

Increased incidence of disability was associated with malnutrition in this study. These results are in agreement with Oliveira et al. [38] who assessed the relationship between nutritional status and indicators of functional capacity among recently hospitalized elderly in a general hospital, and showed that these indicators were significantly more deteriorated among the malnourished individuals [38]. Using mini nutritional assessment (MNA) and Barthel index on 123 resident elderly, Cereda et al. showed that the poorer functional status was associated with low nutrition [39]. Also, Chevalier et al., [40] in a study designed to estimate the prevalence of malnutrition in frail elders undergoing rehabilitation and the association between their nutritional status and physical 
function, showed that there was an interrelationship between nutritional and functional status. It has already been shown that malnutrition compromises the functional status of the individuals [40].

\section{Conclusions}

Results in this study suggest that the hospitalized elderly are exposed to malnutrition, which emphasizes the importance of early identification of malnutrition among them. High nutritional risk was more with older age, rural areas, educated patients, and low income, while gender had no significant effect. Functional abilities were better with younger age but had no significant correlation with other sociodemographic variables. Malnourished hospitalized patients are candidates for functional impairment. Significant associations were noticed between both nutritional and functional status and specific sociodemographic variables. These interrelationships require further studies to elucidate. Also, it is necessary to pay special attention to functional capacity when planning nutritional care for this vulnerable group.

Limitations of This Study. The patients included in this study were a convenient sample from patients admitted to one hospital, so patients from distant areas were not included. The large percent of illiterate patients (84\%) could have an impact on the study. Larger number of patients should be included in future studies.

\section{References}

[1] M. A. Elmadbouly and A. M. AbdElhafez, "Assessment of nutritional status of hospitalized elderly patients in Makkah governorate," Pakistan Journal of Nutrition, vol. 11, no. 10, pp. 886-892, 2012.

[2] R. M. Kleinpell, K. Fletcher, and B. M. Jennings, "Reducing functional decline in hospitalized elderly," in Patient Safety and Quality: An Evidence-Based Handbook ForNurses, R. G. Hughes, Ed., chapter 11, pp. 1-15, AHRQ Publication, 2008.

[3] M. B. Andre, N. Dumavibhat, N. R. Ngatu, M. Eitoku, R. Hirota, and N. Suganuma, "Mini nutritional assessment and functional capacity in community-dwelling elderly in Rural Luozi, Democratic Republic of Congo," Geriatrics and Gerontology International, vol. 13, no. 1, pp. 35-42, 2013.

[4] S. Fang, J. Long, R. Tan et al., "A multicenter assessment of malnutrition, nutritional risk, and application of nutritional support among hospitalized patients in Guangzhou hospitals," Asia Pacific Journal of Clinical Nutrition, vol. 22, no. 1, pp. 54-59, 2013.

[5] J. - Payne-James, G. Grimble, and D. Silk, "Artificial nutrition support," in Clinical Practice, pp. 243-244, GreenwichMedical, London, UK, 2nd edition, 2001.

[6] S. Sinnett, R. Bengle, A. Brown, A. P. Glass, M. A. Johnson, and J. S. Lee, "The validity of nutrition screening initiative DETERMINE checklist responses in older georgians," Journal of Nutrition for the Elderly, vol. 29, no. 4, pp. 393-409, 2010.

[7] M. F. Kuczmarski, D. O. Weddle, and E. M. Jones, "Maintaining functionality in later years: a review of nutrition and physical activity interventions in postmenopausal women," Journal of Nutrition for the Elderly, vol. 29, no. 3, pp. 259-292, 2010.
[8] Y. Tanimoto, M. Watanabe, W. Sun et al., "Association of sarcopenia with functional decline in community-dwelling elderly subjects in Japan," Geriatrics \& Gerontology International, 2013.

[9] J. C. Millán-Calenti, M. Gandoy-Crego, M. Antelo-Martelo, M. López-Martinez, M. P. Riveiro-López, and J. M. Mayán-Santos, "Helping the family carers of Alzheimer's patients: from theory to practice. A preliminary study," Archives of Gerontology and Geriatrics, vol. 30, no. 2, pp. 131-138, 2000.

[10] A. E. Stuck, J. M. Walthert, T. Nikolaus, C. J. Büla, C. Hohmann, and J. C. Beck, "Risk factors for functional status decline in community-living elderly people: a systematic literature review," Social Science and Medicine, vol. 48, no. 4, pp. 445-469, 1999.

[11] D. T. Wade and C. Collin, "The Barthel ADL Index: a standard measure of physical disability?” International Disability Studies, vol. 10, no. 2, pp. 64-67, 1988.

[12] A. Supervéa, D. Aranda, M. A. Márquez, A. Aguirre, E. Skaf, and J. Gutiérrez, "Predicting length of hospitalisation of elderly patients, using the Barthel Index," Age and Ageing, vol. 37, no. 3, pp. 339-342, 2008.

[13] L. E. -Matzen, D. B. Jepsen, J. Ryg, and T. Masud, "Functional level at admission is a predictor of survival in older patients admitted to an acute geriatric unit," BMC Geriatr, vol. 25, pp. 12-32, 2012.

[14] J. Sponton, M. Minosso, F. Amendola, M. R. Alvarenga, and M. A. de Campos Oliveira, "Validation of the Barthel Index in elderly patients attended in outpatient clinics, in Brazil," ACTA Paulista de Enfermagem, vol. 23, no. 2, pp. 218-223, 2010.

[15] The Nutrition Screening Initiative, A Project of: American Academy of Family Physicians, The American Dietetic Association, The National Council on the Aging, Washington, DC, USA, 2007.

[16] A. M. Coulston, L. Craig, and A. C. Voss, "Meals-on-wheels applicants are a population at risk for poor nutritional status," Journal of the American Dietetic Association, vol. 96, no. 6, pp. 570-573, 1996.

[17] D. Rush, "Nutrition screening in old people: its place in a coherent practice of preventive health care," Annual Review of Nutrition, vol. 17, pp. 101-125, 1997.

[18] C. Collin, D. T. Wade, S. Davies, and V. Horne, "The barthel ADL index: a reliability study," International Disability Studies, vol. 10, no. 2, pp. 61-63, 1988.

[19] L. Z. Rubenstein, "Geriatric assessment: an overview of its impacts," Clinics in Geriatric Medicine, vol. 3, no. 1, pp. 1-15, 1987.

[20] J. K. Luk, K. H. Or, and J. Woo, "Using the comprehensive geriatric assessment technique to assess elderly patients," Hong Kong Medical Journal, vol. 6, no. 1, pp. 93-98, 2000.

[21] J. M. Bauer, M. J. Kaiser, P. Anthony, Y. Guigoz, and C. C. Sieber, "The mini nutritional assessment-its history, today's practice, and future perspectives," Nutrition in Clinical Practice, vol. 23, no. 4, pp. 388-396, 2008.

[22] ADA Reports, "Position of the American Dietetic Association: liberalization of the diet prescription improves quality of life for older adults in long-term care," Journal of the American Dietetic Association, vol. 105, no. 12, pp. 1955-1965, 2005.

[23] B. M. Posner, A. M. Jette, K. W. Smith, and D. R. Miller, "Nutrition and health risks in the elderly: the nutrition screening initiative," American Journal of Public Health, vol. 83, no. 7, pp. 972-978, 1993.

[24] D. L. MacLellan and L. D. van Til, "Screening for nutritional risk among community-dwelling elderly on Prince Edward Island," 
Canadian Journal of Public Health, vol. 89, no. 5, pp. 342-346, 1998.

[25] S. Baweja, H. Agarwal, A. Mathur et al., "Assessment of nutritional status and related risk factors in community dwelling elderly in Western Rajastha," Journal of the Indian Academy of Geriatrics, vol. 4, no. 1, pp. 5-13, 2008.

[26] K. B. Yap, M. Niti, and T. P. Ng, "Nutrition screening among community-dwelling older adults in Singapore," Singapore Medical Journal, vol. 48, no. 10, pp. 911-916, 2007.

[27] J. Rambousková, M. Slavíková, A. Krsková, B. Procházka, and A. Dlouhý, "Nutritional Status Assessment of Institutionalized Elderly in Prague, Czech Republic," Annals of Nutrition \& Metabolism, vol. 62, no. 3, pp. 199-204, 2013.

[28] O. Ibiyemi, O. Ketiku, and A. Olubode, "Socio-demographic and nutritional assessment of the elderly Yorubas in Nigeria," Asia Pacific Journal of Clinical Nutrition, vol. 15, no. 1, pp. 95101, 2006.

[29] C. MacIntosh, J. E. Morley, and I. M. Chapman, “The anorexia of aging," Nutrition, vol. 16, no. 10, pp. 983-995, 2000.

[30] F. I. Mahoney and D. W. Barthel, "Functional evaluation: the barthel index," Maryland state medical journal, vol. 14, pp. 6165, 1965.

[31] C. V. Granger, L. S. Dewis, N. C. Peters, C. C. Sherwood, and J. E. Barrett, "Stroke rehabilitation: analysis of repeated barthel index measures," Archives of Physical Medicine and Rehabilitation, vol. 60, no. 1, pp. 14-17, 1979.

[32] J. C. Hobart, D. L. Lamping, J. A. Freeman et al., "Evidencebased measurement: which disability scale for neurologic rehabilitation?" Neurology, vol. 57, no. 4, pp. 639-644, 2001.

[33] I.-P. Hsueh, J.-H. Lin, J.-S. Jeng, and C.-L. Hsieh, “Comparison of the psychometric characteristics of the functional independence measure, 5 item Barthel index, and 10 item Barthel index in patients with stroke," Journal of Neurology Neurosurgery and Psychiatry, vol. 73, no. 2, pp. 188-190, 2002.

[34] J. J. van der Putten, J. C. Hobart, J. A. Freeman, and A. J. Thompson, "Measuring change in disability after inpatient rehabilitation: comparison of the responsiveness of the Barthel index and the functional independence measure," Journal of Neurology Neurosurgery and Psychiatry, vol. 66, no. 4, pp. 480484, 1999.

[35] N. N. Hairi, A. Bulgiba, R. G. Cumming, V. Naganathan, and I. Mudla, "Prevalence and correlates of physical disability and functional limitation among community dwelling older people in rural Malaysia, a middle income country," BMC Public Health, vol. 10, article 492, 2010.

[36] A. Koster, H. Bosma, M. I. Broese van Groenou et al., "Explanations of socioeconomic differences in changes in physical function in older adults: results from the longitudinal aging study Amsterdam," BMC Public Health, vol. 6, article 244, 2006.

[37] L. Bergamini, M. Burgoni, G. Federzoni et al., "Multidimensional evaluation of home-dwelling elderly: the impact of medical and social factors on health status indices," Archives of Gerontology and Geriatrics, vol. 44, supplement, pp. 75-81, 2007.

[38] M. R. Oliveira, K. C. Fogaça, and V. A. Leandro-Merhi, "Nutritional status and functional capacity of hospitalized elderly," Nutrition Journal, vol. 8, no. 1, article 54, 2009.

[39] E. Cereda, L. Valzolgher, and C. Pedrolli, "Mini nutritional assessment is a good predictor of functional status in institutionalised elderly at risk of malnutrition," Clinical Nutrition, vol. 27, no. 5, pp. 700-705, 2008.
[40] S. Chevalier, F. Saoud, K. Gray-Donald, and J. A. Morais, "The physical functional capacity of frail elderly persons undergoing ambulatory rehabilitation is related to their nutritional status," Journal of Nutrition, Health and Aging, vol. 12, no. 10, pp. 721726, 2008. 


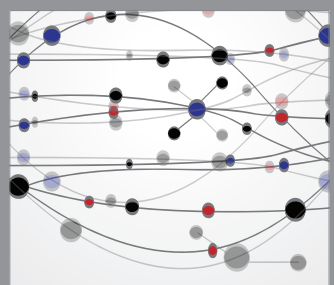

The Scientific World Journal
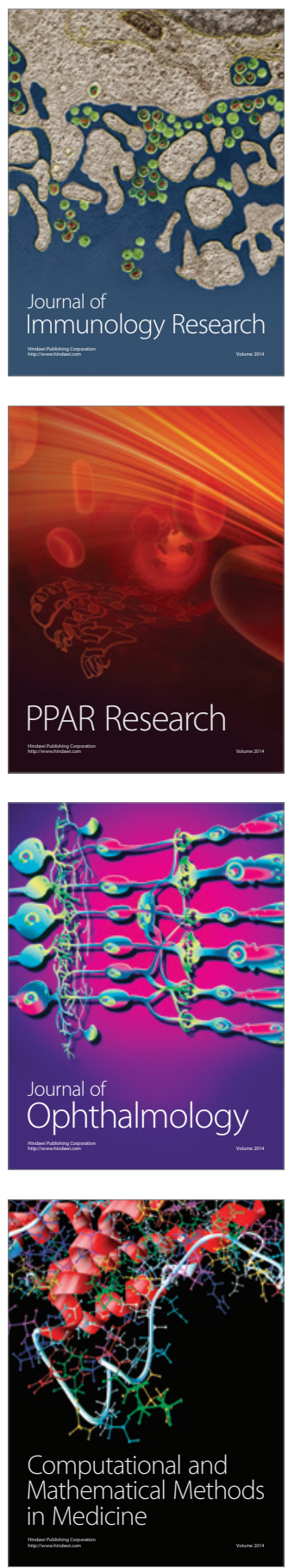

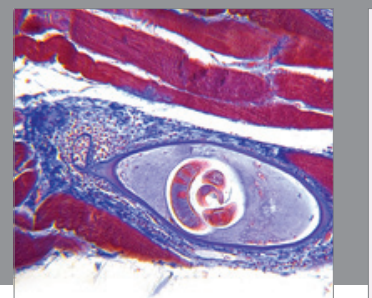

Gastroenterology

Research and Practice
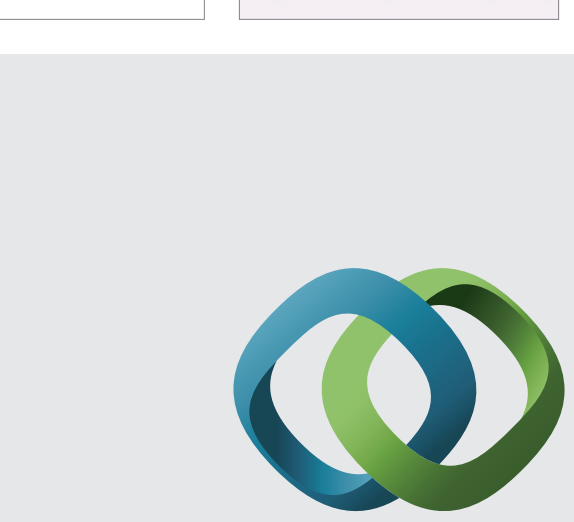

\section{Hindawi}

Submit your manuscripts at

http://www.hindawi.com
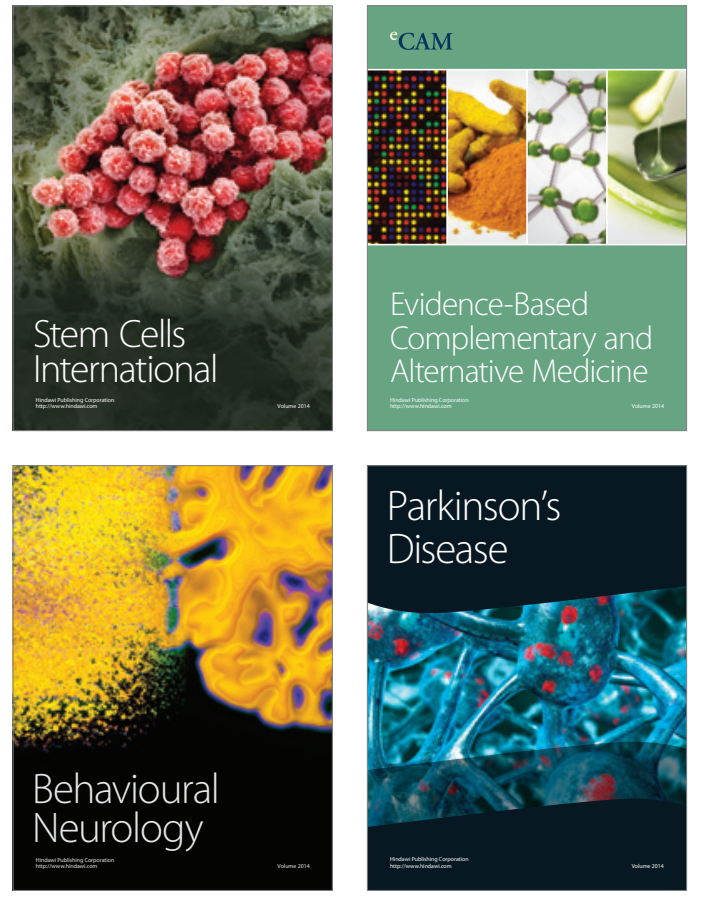
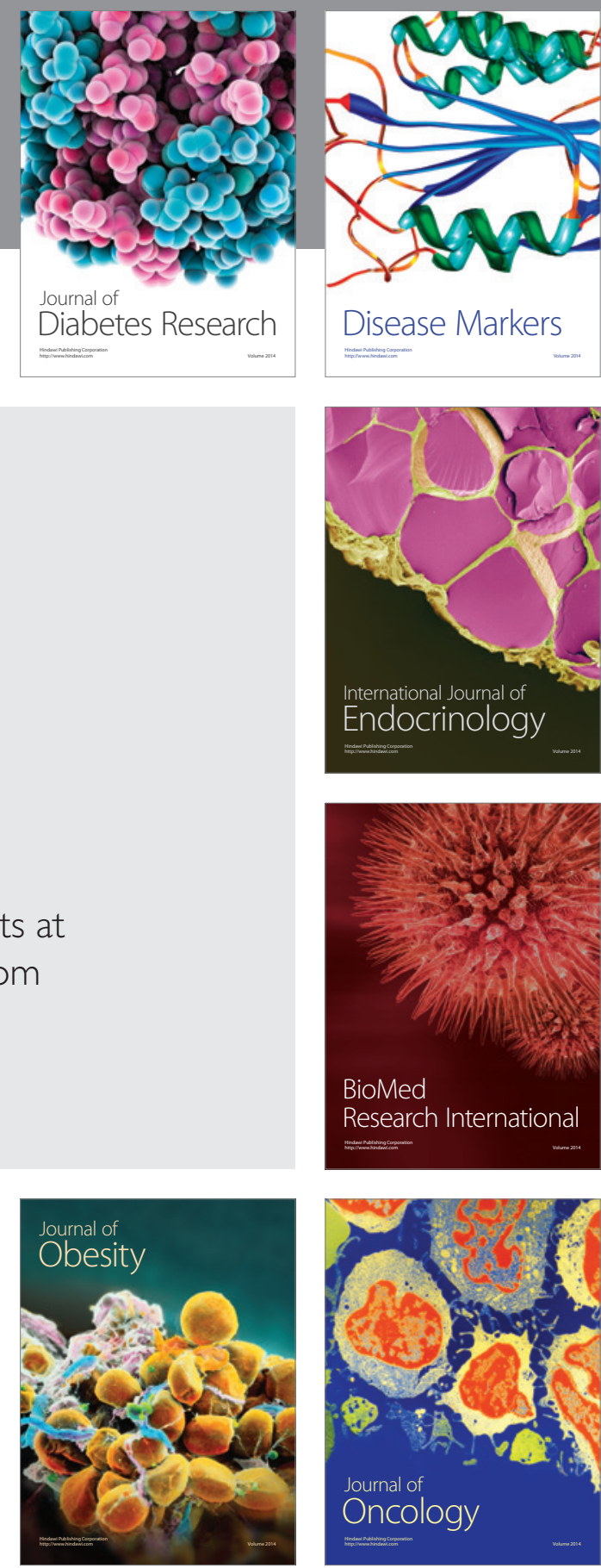

Disease Markers
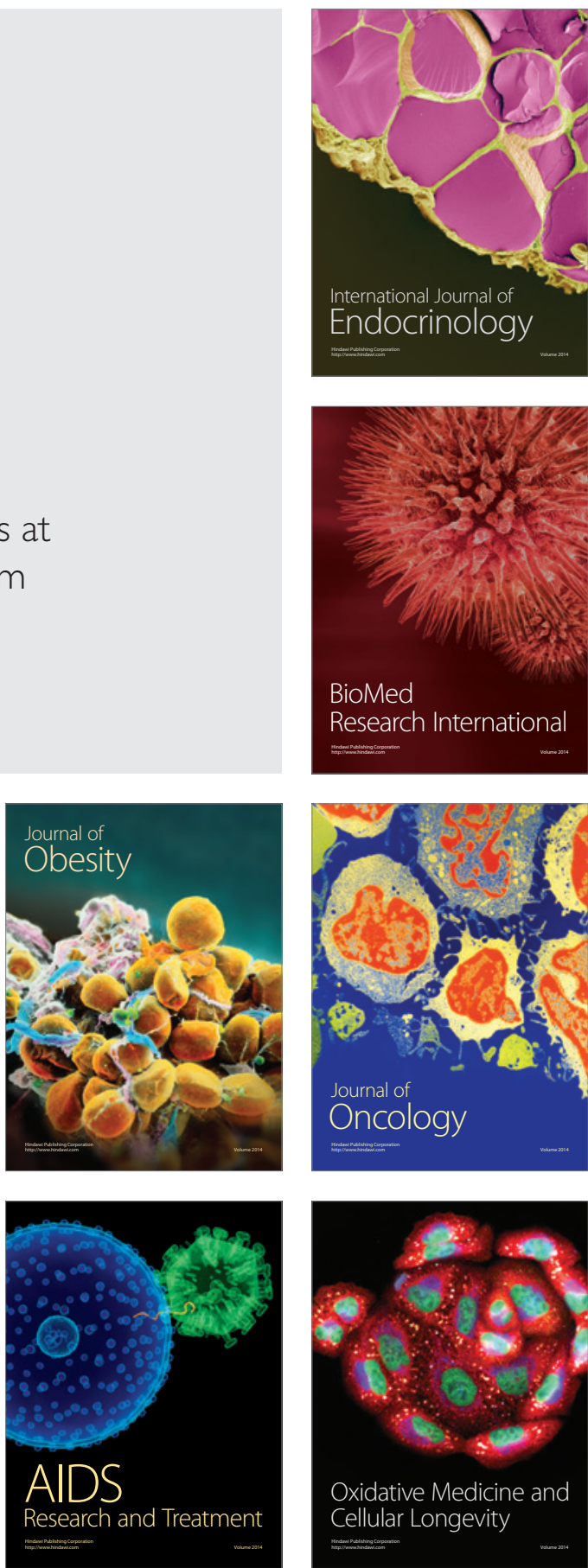